\title{
Jaya algorithm for design optimization of planar steel frames
}

\author{
İbrahim Behram UĞUR*1 ${ }^{* 1}$, Sadık Özgür DEĞERTEKİN ${ }^{2}$ \\ ${ }^{1}$ Dicle University, Civil Engineering Department, behramugur@gmail.com, Orcid No: 0000-0002-0950-4876 \\ 2 Dicle University, Civil Engineering Department, sozgur@ dicle.edu.tr, Orcid No 0000-0001-8885-6468
}

\begin{tabular}{|c|c|}
\hline ARTICLE INFO & ABSTRACT \\
\hline $\begin{array}{l}\text { Article history: } \\
\text { Received 1 September } 2021 \\
\text { Received in revised form } 22 \text { October } 2021 \\
\text { Accepted } 22 \text { October } 2021 \\
\text { Available online } 31 \text { December } 2021\end{array}$ & $\begin{array}{l}\text { An efficient metaheuristic optimization method called Jaya Algorithm (JA) has gained wide acceptance } \\
\text { among optimization researchers in various engineering problems recently. The main feature of JA is that } \\
\text { it does not use algorithm-specific parameters and has a very simple formulation based on the concept of } \\
\text { approaching the best solution and moving away from the worst solution. This study presents the JA }\end{array}$ \\
\hline $\begin{array}{l}\text { Keywords: } \\
\text { design optimization, planar steel } \\
\text { frames, metaheuristic optimization }\end{array}$ & $\begin{array}{l}\text { formulation for design optimization of planar steel frames under strength and displacement constraints. } \\
\text { The validity of JA is investigated by solving two benchmark design examples. The results demonstrated } \\
\text { the superiority of JA over other state-of-the-art metaheuristic optimization methods in terms of optimized } \\
\text { weight, number of structural analyses and several statistical parameters. }\end{array}$ \\
\hline
\end{tabular}

Doi: $10.24012 / d u m f .1051486$

* Corresponding author

\section{Introduction}

The metaheuristic optimization methods that mimic natural phenomena has been implemented for solving different design problems over the past three decades. A metaheuristic could be defined as the process of an iterative generation which sheds light on a heuristic by incorporating smartly different concepts for exploration and exploitation of the search space and achieving strategies in order to find near-optimum solutions [1]. Exploration and exploitation are the most significant concepts of finding the best solution in all metaheuristic optimization methods. Exploration provides generating diverse solutions in order to explore search space on a global scale whereas exploitation focuses on the search in a local region by exploiting the information. The balance between exploration and exploitation allows to identify regions containing high-quality solutions and move away from previously explored regions that are far from global optimum.

In the last two decades, the bio-inspired approaches (Genetic algorithm (GA) [2], Particle swarm (PSO) [3], Ant colony (ACO) [4], Honey bee mating (HBMO) [5], Enhanced honey bee mating (EHBMO) [6], Whale optimization algorithm (WOA) [7], Enhanced whale optimization algorithm (EWOA) [8] etc.) and physicinspired approaches (Simulating annealing (SA) [9], Harmony search (HS) [10], Big-bang big-crunch [11],
Colliding bodies (CBO) [12] etc.) have been proposed for the optimization problems and extended by enhancing their capabilities in optimization procedures such as the convergence, time consumption and achieving the nearglobal optima.

The structures should be designed by determining the optimum cross-sectional areas so as not to exceed the strength and displacement limits given in the relevant specifications. Meanwhile, resource and time management are some of the most challenging problems in structural engineering; however, structural designers can overcome these problems using metaheuristics to obtain the best design in terms of cost and safety. Since frame structures constitute the vast majority of the skeletal systems in structural engineering, the design optimization (i.e. optimum design) of planar steel frames is a common selected issue as a benchmark problem to investigate the efficiency of novel metaheuristics. Hence, various optimization methods have been proposed for the design optimization of steel frames under strength and displacement constraints specified in design specifications.

Just to overview the literature published in the past two decades, Camp et. al. [13] used the ant colony algorithm (ACO) that is to simulate the ant behavior to structural optimization of steel frames. Degertekin [14] utilized the harmony search (HS) based on the concept of searching for 
the best harmony in musical improvisation. The efficiency of HS was tested in the design optimization of planar steel frames in comparison with the genetic algorithm and ant colony optimization methods. In the study proposed by Saka [15], structural optimization algorithms including GA, SA and HS were reviewed and assessed comparing the optimization results of a steel frame design example for each method. Genetic algorithms, simulated annealing, evolution strategies, particle swarm optimizer, tabu search, ant colony optimization and harmony search are used for optimum design of real size steel frames by Hasancebi et al. [16]. Dogan and Saka [17] developed an optimum design algorithm based on particle swarm optimizer for planar steel frames. The superiority of the proposed algorithm was verified by optimizing three steel frames in comparison to SA and GA. An enhanced honey bee mating optimization method (EHBMA) for the optimum design of side sway steel frames was proposed by Maheri and Nerimani [6] in order to overcome trapping local optima and extend the search space of HBMO. The performance of the new method was evaluated with four design examples. Kaveh and Gaazan [8] proposed a new method called enhanced whale optimization algorithm (EWOA) to enhance the convergence speed and solution accuracy of the standard whale optimization algorithm (WOA). The efficiency of the EWOA was tested with four benchmark skeletal structures and the results were compared to standard WOA and other optimization methods. Carrero et. al. [18] implemented a search group algorithm (SGA) to three steel frame examples in order to investigate the efficiency of the method. The results demonstrated that the proposed method achieved competitive performance. Farshchin et. al. [19] applied a school-based optimization (SBO) algorithm that is an enhanced version of teaching-learning based optimization (TLBO) including multiple classrooms and multiple teachers for the optimum design of planar steel frames.

Most evolutionary and swarm-based intelligence algorithms require algorithm-specific parameters for tuning the optimization process. However, if the optimal parameter values cannot be obtained, the computational cost or convergence ability of the method will be adversely affected. In order to overcome this drawback, Rao [20] proposed a parameter-less evolutionary algorithm that has a powerful search engine and can be easily implemented for any optimization problem. The JA and its enhanced versions with various strategies have been utilized in largescale real-life urban traffic light scheduling problems [21], parameter estimating of battery models [22], cost minimization of underground cable systems [23], structural damage detection [24]. Besides, the JA was used also for the optimum design of truss structures with both discrete and continuous variables [25,26]. The satisfactory performance of the JA in sizing optimization of truss structures encouraged the authors to use JA in the structural optimization of planar steel frames.

The main objective of this study is to minimize the weight of planar steel frames with the design constraints of American Institute of Steel Construction-Load and Resistance Factor Design (AISC-LRFD) [27] by using the
JA. For this purpose, JA is applied to the design optimization of the two planar frames utilized as the classical benchmark problems in the literature.

The remaining parts of the study are organized as follows: Section 2 recalls the discrete sizing optimization of planar steel frames according to AISC-LRFD [27]. Section 3 outlines the main steps for the implementation of the JA. Section 4 describes the benchmark problems and discusses optimization results. Section 5 provides a brief conclusion of the study.

\section{Design optimization of planar steel frames}

Design optimization is the one with the minimum weight among the designs that satisfy the constraints. Crosssectional areas are selected as design variables in the optimization problem. The objective of the optimization problem is to minimize the weight of steel frames under strength and displacement constraints by assigning the most proper steel profiles in a ready section list. The formulation of design optimization problem of planar frames can be stated as:

Find

$$
A \in S=\left\{A_{1}, A_{2}, \ldots, A_{i}, \ldots, A_{n c s}\right\}
$$

to minimize

$$
W(A)=\sum_{k=1}^{n g} A_{k} \sum_{i=1}^{n m} \gamma_{i} L_{i}
$$

$k=1,2, \ldots ., n g \quad i=1,2, \ldots, n m$

$$
\text { subject to } \quad g_{j}(A) \leq 0 \quad j=1,2 \ldots n c
$$

where $A$ is the vector including the design variables (i.e. member groups), $S$ is the ready section list consists of steel profiles, $W(A)$ is the total weight of structure defined as an object function, $\gamma_{i}$ and $L_{i}$ are the material density and the length of $i$-th member, $A_{i}$ is the cross-sectional area of the $i$-th member, $g_{j}(A)$ denotes the design constraints including strength and displacement constraints, $n c$ is number of design constraints, $n g$ is number of member group (i.e. design variables), $n m$ is the number of members, $n c s$ is the number of discrete cross-sectional areas in the steel profile list.

A penalty approach is utilized to distinguish the designs that satisfy or not satisfy design constraints. Accordingly, the penalized objective function is defined as follows:

$$
\begin{gathered}
W_{p}(A)=\left(1+\varepsilon_{1} \times \psi\right)^{\varepsilon_{2}} \times W(A) \\
\psi=\sum_{j=1}^{n} \max \left[0, g_{j}(A)\right]
\end{gathered}
$$

where $g_{j}(A)$ is the maximum violation values for each design constraint, $n$ is the number of design constraints, $\psi$ represents the sum of the violated constraints. $\varepsilon_{1}$ is the penalty constant set to $1, \varepsilon_{2}$ is the exponent of the penalty function taken as 2 . The penalty parameters allow the objective function to approach in a feasible direction. 


\section{Constraints used in design optimization of frames}

The design optimization of steel frames is subjected to displacement and strength constraints specified in the AISC-LRFD [27]. Strength constraints are described as following interaction equations expressed in AISC-LRFD against both bending and axial forces:

$$
\begin{gathered}
\text { if } \frac{P_{u}}{\phi_{c} P_{n}} \geq 0.2 \\
g_{s, i}(A)=\frac{P_{u}}{\phi_{c} P_{n}}+\frac{8}{9}\left(\frac{M_{u x}}{\phi_{b} M_{n x}}+\frac{M_{u y}}{\phi_{b} M_{n y}}\right)-1 \leq 0 \\
\text { if } \frac{P_{u}}{\phi_{c} P_{n}}<0.2 \\
g_{s, i}(A)=\frac{P_{u}}{2 \phi_{c} P_{n}}+\left(\frac{M_{u x}}{\phi_{b} M_{n x}}+\frac{M_{u y}}{\phi_{b} M_{n y}}\right)-1 \leq 0
\end{gathered}
$$

where $g_{s, j}(A)$ denotes the strength constraint for $i$-th member, $P_{u}$ and $P_{n}$ represent the required axial strength and the nominal axial strength for both compression and tension; $M_{u x}$ and $M_{n x}$ denote required flexural strength and nominal flexural strength about the $x$-direction (major axis); $M_{u y}$ and $M_{n y}$ are the required flexural strength and nominal flexural strength about the $y$-direction (minor axis). It should be noted that $M_{n y}=0$ for planar frames. $\phi_{c}$ is the axial resistance factor and taken as 0.90 for tension and 0.85 for compression; $\phi_{b}$ is the flexural resistance reduction factor and taken as 0.90 .

Lateral displacement and interstory drift constraints used in this study could be defined as follows:

$$
\begin{gathered}
g_{d}(A)=\frac{\Delta_{T}}{H}-R \leq 0 \\
g_{i s, n}(A)=\frac{d_{n}}{h_{n}}-R_{I} \leq 0 \quad n=1,2 \ldots n s
\end{gathered}
$$

where $g_{d}(A)$ and $g_{i s, n}(A)$ are the lateral displacement and interstory drift constraints, $\Delta_{T}$ is the lateral displacement of the top story, $H$ is the total height of the steel frame, $R$ is the maximum displacement limit taken as $1 / 300, d_{n}$ is the interstory drift of the $n$-th story, $h_{n}$ is the height of the $n$-th story. $n s$ is the number of stories. $R_{I}$ denotes the interstory limit value specified as $1 / 300$.

\section{Jaya Algorithm (JA)}

The JA recently developed optimization method is firstly proposed by Rao [20]. The word "Jaya" originally means "victory" in Sanskrit. The algorithm is based on the concept that the solution obtained for a given optimization problem should move toward the best solution and must avoid the worst solution. The algorithm always tries to get closer to success (i.e. reaching the best design) and then tries to avoid failure (i.e. moving away from the worst design) [20]. The most important feature of JA is not to have any algorithmspecific parameters unlike other metaheuristic. The JA only requires two standard control parameters which are the population size (i.e. number of steel design in the population) and maximum iteration number.

The implementation of JA is very simple and has only one equation for modifying the designs. $A_{k, 1, i t}$ denotes the value of the $\mathrm{k}$-th design variable for the 1-th design during the it-th iteration, the JA modifies the $A_{k, 1, i t}$ as follows:

$$
\begin{aligned}
A_{k, l, i t}^{\text {new }}=A_{k, l, i t}+ & r_{1, k, i t}\left(A_{k, \text { best }, i t}-\left|A_{k, l, i t}\right|\right) \\
& -r_{2, k, i t}\left(A_{k, \text { worst }, i t}-\left|A_{k, l, i t}\right|\right)
\end{aligned}
$$

where $A_{k, l, i t}^{\text {new }}$ is the new design variable for the $A_{k, l, i t}, r_{1, k, i t}$ and $r_{2, k, i t}$ are the randomly generated real numbers in the range $[0,1]$ for the $k$-th design variable at the it-th iteration. $A_{k, b e s t, i t}$ is the $k$-th design variable of the best design at the it-th iteration and $A_{k, \text { worst,it }}$ is the $k$-th design variable of the worst design at the it-th iteration. The term $r_{1, k, i t}\left(A_{k, b e s t, i t}-\left|A_{k, l, i t}\right|\right)$ indicates the tendency of the solution to move closer to the best solution, and the term $-r_{2, k, i t}\left(A_{k, \text { worst }, i t}-\left|A_{k, l, i t}\right|\right)$ indicates the tendency of the solution to avoid the worst solution. It is worth pointing out that the random numbers $r_{l}$ and $r_{2}$ ensure good exploration of the search space and the absolute value of the candidate solution $\left(\left|A_{k, l, i t}\right|\right)$ considered in Eq. (8) further enhances the exploration ability of the algorithm [20].

As mentioned earlier, JA has no algorithm-specific parameter and only needs common control parameters as population size (np) and maximum iteration number $\left(i t_{\max }\right)$. The optimization is terminated when the maximum iteration number is exceeded. However, each optimization run could find the best solution for a different value of $i t_{\max }$. Sensitivity analyses are required in order to find the most appropriate $i t_{\max }$ value in each design example. Instead, the following formulation is implemented to terminate the search process when it is satisfied:

$$
\frac{S T D\left[W_{p}\left(A^{1}\right), W_{p}\left(A^{2}\right), \ldots W_{p}\left(A^{n p}\right)\right]}{\sum_{i=1}^{n s}\left(\frac{1}{W_{p}\left(A^{i}\right)}\right)} \leq \varepsilon_{c o n}
$$

where STD stands for the standard deviation, $W_{p}\left(A^{i}\right)$ is the penalized objective function of $i$-th design in the population, $n p$ is the population size, $\varepsilon_{\text {con }}$ is the coefficient of convergence tolerance taken as $10^{-4}$.

\section{Implementation of JA for design optimization of steel frames}

In design optimization of steel frames, the JA is initialized by randomly generated frame designs as the population size $n p$ (i.e. number of frame designs) and the penalty functions for each design are calculated by the results of structural analysis. The penalized functions are calculated at the rate of constraint violation. After that, the frame design with the lowest penalized function value $W_{p}\left(A_{i}^{\text {best }}\right)$ and the highest penalized function value $W_{p}\left(A_{i}^{\text {worst }}\right)$ is assigned to the best design and the worst design, respectively. Design variables are modified using Eq. (8). The new frame design is generated with modified design 
variables. The new penalized objective function $W_{p, \text { new }}(A)$ is calculated. If the new penalized objective function value is less than the previous one, $\left(W_{p, \text { new }}(A)<W_{p, \text { pre }}(A)\right)$, the new design is replaced with the previous one. Otherwise, the previous design remains unchanged. This process is repeated for each frame design in the population, and then an iteration is completed. The optimization is terminated when the Eq. (9) is satisfied. The best design without constraint violation is reported as the optimum design.

The implementation of JA for design optimization of steel frames is summarized below.

Step 1: Generate the initial population (i.e. steel frame designs) Calculate the penalized objective function values $W_{p}(A)$ for all frame designs in the population using Eqs. (1-7). Set the iteration counter as $i t=0$.

Step 2: Increase the iteration counter, $i t=i t+1$

Step 3: Determine the best and worst design of the population.

Step 4: Modify design variables of a steel frame by using Eq. (8) in the population. Obtain the new design by modifying design variables $\left(A^{\text {new }}\right)$ and calculate the penalized function value $W_{p}\left(A^{\text {new }}\right)$.

Step 5: If $W_{p}\left(A_{i}^{\text {new }}\right)<W_{p}\left(A_{i}^{\text {pre }}\right)$, replace the $i$-th new design with the previous one, otherwise; unchanged the previous design. Repeat steps 4 and 5 for each frame design stored in the population.

Step 6: Terminate the optimization process if Eq. (9) is satisfied. Select the feasible design with the lowest objective function as the final optimum design. Otherwise, go to Step 2

\section{Design Examples}

To demonstrate the performance of JA, two benchmark frame examples as follows: three-bay fifteen-story steel frame and a three-bay twenty four-story steel frame are optimized according to provisions of AISC-LRFD [27] and the results are compared with other metaheuristic methods in the literature.

The JA was executed ten different times by using ten different initial populations. The population size was set to 20 for all examples. The statistical performance and robustness of algorithms are assessed and reported in related tables. The best, mean and worst weights for ten different runs are reported in the tables. The standard deviation of ten runs and number of structural analyses for the best design are also presented in tables. The optimum design of each example reported in other referenced studies was analysed using the given optimum steel profiles in order to check their constraint violations. If detected, the maximum violation percent of design constraints are reported in the tables.

The main program included JA was coded in the MATLAB R2017a [28], however; the structural analyses of steel frames are performed by OPENSEES [29]. Therefore, optimum design is carried out by constantly interacting with MATLAB and OPENSEES.

\section{Three-Bay Fifteen-Story Frame}

Three-bay fifteen-story planar frame was optimized firstly by Saka [15] using SA and GA according to AISC-LRFD [27]. The geometry and load conditions of the frame are shown in Figure 1. The frame consists of 105 members divided into 12 design groups. Member grouping is considered as consecutive three-story inner and outer columns form a distinct group, roof and intermediate story beams constitute a distinct group. The frame is subjected to gravity loading as well as wind loading considering $45 \mathrm{~m} / \mathrm{s}$ wind speed and $6 \mathrm{~m}$ frame spacing [15]. The modulus of elasticity is $200 \mathrm{kN} / \mathrm{mm}^{2}$. In this example, both interstory drift and lateral displacement of the top story are considered as displacement constraints and restricted to be smaller than $1.17 \mathrm{~cm}$ and $17.67 \mathrm{~cm}$, respectively.

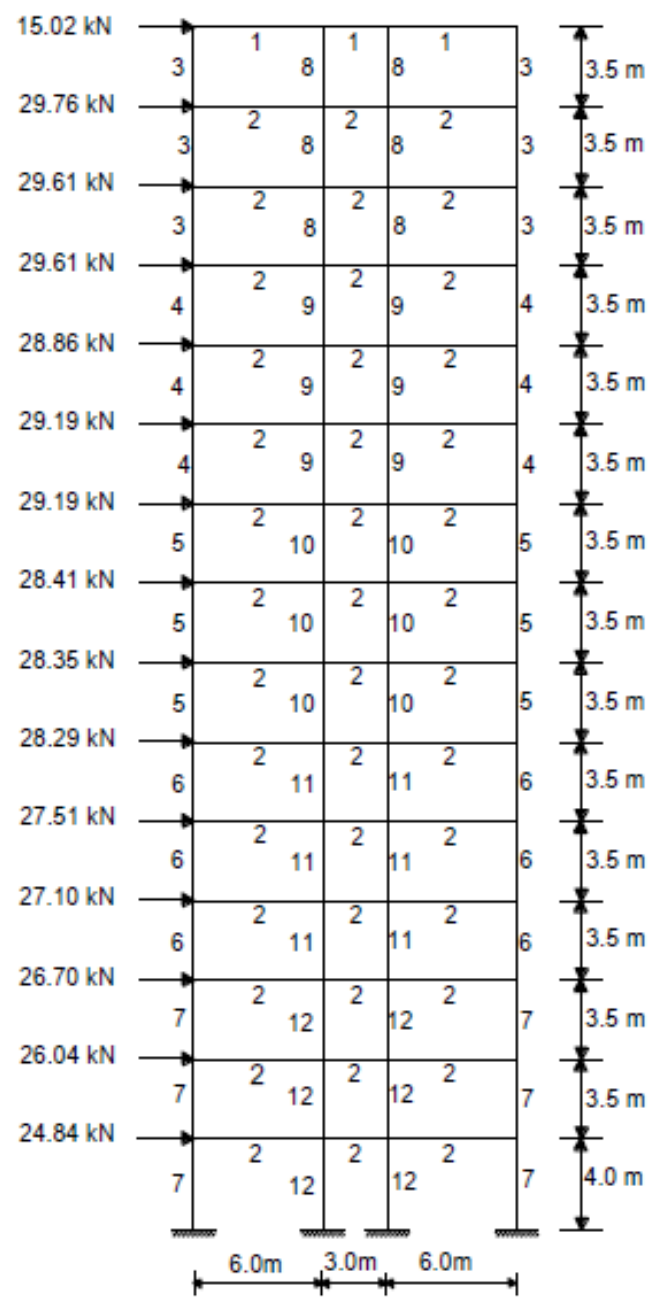

Figure 1. Three-bay fifteen-story frame

The optimum design results of JA and other methods in the literature are reported in Table 1. JA obtained the best design weighing of $34103 \mathrm{~kg}$ which is $\% 8.71$ lighter than the best design obtained using PSO [17], \%13.1 lighter than the SA and $\% 16.7$ lighter than GA [15]. In addition, JA has found better a design with less structural analysis with lower standard deviation than the others. The maximum lateral displacement and interstory drift are $13.18 \mathrm{~cm}$ and $1.16 \mathrm{~cm}$, respectively. 
Besides, interaction ratio is 0.99 which means strength constraints govern the optimization process. It should be noted that the JA strictly satisfies the design constraints, however; PSO [17] violated displacement constraint as shown in Table 1.

Table 1. Comparison of optimum designs for three-bay fifteenstorey frame

\begin{tabular}{|c|c|c|c|c|}
\hline $\begin{array}{l}\text { Design } \\
\text { variables }\end{array}$ & $\begin{array}{l}\text { GA } \\
{[15]}\end{array}$ & $\begin{array}{l}\text { SA } \\
{[15]}\end{array}$ & $\begin{array}{l}\text { PSO } \\
{[17]}\end{array}$ & $\begin{array}{l}\text { JA } \\
\text { This } \\
\text { study }\end{array}$ \\
\hline 1 & $\mathrm{~W} 21 \times 50$ & $\mathrm{~W} 21 \times 50$ & $\mathrm{~W} 6 \times 9$ & W8 $\times 21$ \\
\hline 2 & W24×55 & $\mathrm{W} 21 \times 57$ & $\mathrm{~W} 21 \times 44$ & W21 $\times 44$ \\
\hline 3 & $\mathrm{~W} 10 \times 39$ & $\mathrm{~W} 10 \times 33$ & $\mathrm{~W} 10 \times 33$ & W14 $\times 30$ \\
\hline 4 & W14×53 & $\mathrm{W} 10 \times 39$ & $\mathrm{~W} 10 \times 33$ & $W 16 \times 40$ \\
\hline 5 & W14×53 & $\mathrm{W} 12 \times 53$ & $\mathrm{~W} 14 \times 53$ & $\mathrm{~W} 18 \times 50$ \\
\hline 6 & W14×68 & $\mathrm{W} 16 \times 67$ & $\mathrm{~W} 21 \times 111$ & $W 24 \times 68$ \\
\hline 7 & W $24 \times 117$ & W24×104 & $\mathrm{W} 21 \times 111$ & W24×104 \\
\hline 8 & W14×43 & $\mathrm{W} 10 \times 39$ & $\mathrm{~W} 14 \times 61$ & $W 8 \times 28$ \\
\hline 9 & W14×48 & $\mathrm{W} 14 \times 48$ & $\mathrm{~W} 14 \times 61$ & W14×43 \\
\hline 10 & W14×68 & $\mathrm{W} 14 \times 61$ & $\mathrm{~W} 24 \times 76$ & $W 21 \times 62$ \\
\hline 11 & W14×109 & W14×99 & W27×94 & $\mathbf{W 3 0} \times 90$ \\
\hline 12 & $\mathrm{~W} 16 \times 100$ & W14×99 & $\mathrm{W} 27 \times 102$ & W30 $\times 108$ \\
\hline $\begin{array}{l}\text { Best } \\
\text { weight }(\mathrm{kg})\end{array}$ & 40949 & 39262 & 37360 & 34103 \\
\hline NSA & 25000 & 15500 & 7000 & 7870 \\
\hline $\begin{array}{l}\text { Mean } \\
\text { weight }(\mathrm{kg})\end{array}$ & N/A & N/A & N/A & 35381 \\
\hline $\begin{array}{l}\text { Worst } \\
\text { weight }(\mathrm{kg})\end{array}$ & N/A & N/A & N/A & 37395 \\
\hline SD & N/A & N/A & N/A & 1366 \\
\hline $\operatorname{Max} \mathrm{CV}(\%)$ & None & None & 116 & None \\
\hline
\end{tabular}

The design history graph of optimization using PSO [17] and JA is plotted in Fig. 8. The convergence of JA is rather satisfying in comparison with PSO [17].

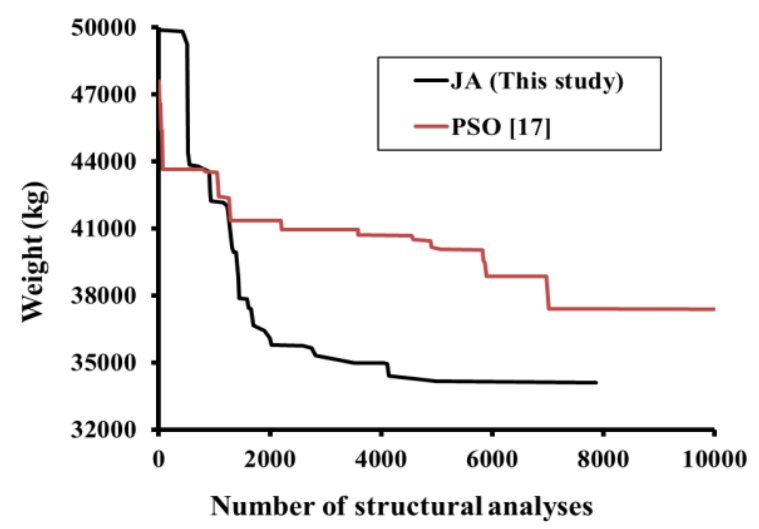

Figure 2. Comparison of convergence curves for the three-bay fifteen-story frame

\section{Three-Bay Twenty-Four Story Frame}

The second benchmark example is the three-bay twentyfour story frame consisting of 168 members that are collected in 20 groups shown in Fig. 3. The frame was originally designed by Davison and Adams [31], later optimized by PSO [13], HS [14], SGA [18], HBMO and EHBMO [6], WOA and EWOA [8] and SBO [19]. The material modulus of elasticity is $29782 \mathrm{ksi}(205340 \mathrm{MPa})$ and the yield stress is taken as $33.4 \mathrm{ksi}(230.3 \mathrm{MPa})$. All members are considered unbraced along their lengths. For each column, the effective length factor is calculated according to equations proposed by Dumonteil [30] for sway-permitted frames. The effective length factor of the out-of-plane columns $\left(K_{y}\right)$ is considered as 1.0. The beam member groups could be selected from $\mathrm{W}$-shaped sections in AISC standard profile list while the column members are limited to W14 cross-sections. The member grouping scheme is demonstrated in Fig. 3. Since all results in the literature are reported in imperial units, same units are used in here to prevent rounding errors. Table 2 lists results of optimum designs including $\mathrm{JA}$ and other referenced optimization methods.

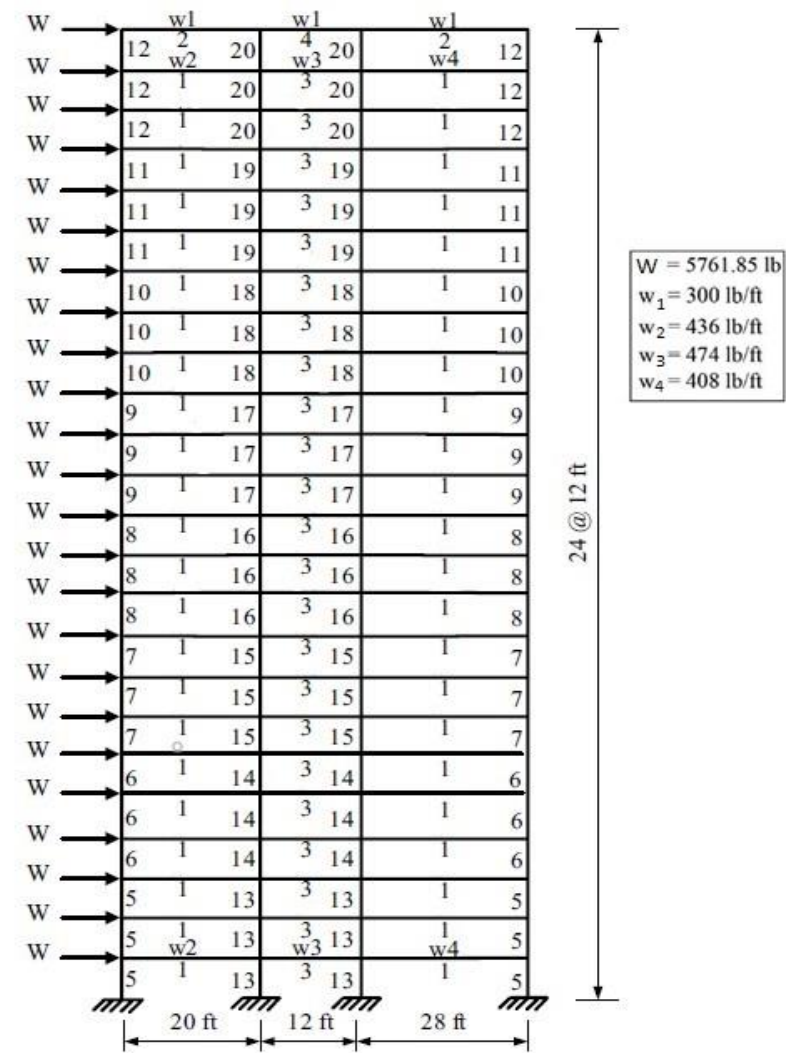

Figure 3. Three-bay twenty-four story frame $(1 \mathrm{ft}=30.48 \mathrm{~cm})$ 


\begin{tabular}{|c|c|c|c|c|c|c|c|c|c|}
\hline $\begin{array}{l}\text { Design } \\
\text { variables }\end{array}$ & $\begin{array}{l}\mathrm{ACO} \\
{[13]}\end{array}$ & $\begin{array}{l}\text { HS } \\
{[14]}\end{array}$ & $\begin{array}{l}\text { SGA } \\
{[18]}\end{array}$ & $\begin{array}{l}\text { HBMO } \\
{[6]}\end{array}$ & $\begin{array}{l}\text { EHBMO } \\
{[6]}\end{array}$ & $\begin{array}{l}\text { WOA } \\
{[8]}\end{array}$ & $\begin{array}{l}\text { EWOA } \\
{[8]}\end{array}$ & $\begin{array}{l}\text { SBO } \\
{[19]}\end{array}$ & $\begin{array}{l}\text { JA } \\
\text { This } \\
\text { study }\end{array}$ \\
\hline 1 & $\mathrm{~W} 30 \times 90$ & $\mathrm{~W} 30 \times 90$ & W24×68 & $\mathrm{W} 10 \times 22$ & $\mathrm{~W} 10 \times 15$ & $\mathrm{~W} 30 \times 90$ & $\mathrm{~W} 30 \times 90$ & $\mathrm{~W} 30 \times 90$ & W30×90 \\
\hline 2 & $\mathrm{~W} 8 \times 18$ & $\mathrm{~W} 10 \times 22$ & W21×55 & W27×539 & W36×256 & $\mathrm{W} 10 \times 17$ & $\mathrm{~W} 10 \times 30$ & $\mathrm{~W} 8 \times 18$ & W6 $\times 15$ \\
\hline 3 & $\mathrm{~W} 24 \times 55$ & $\mathrm{~W} 18 \times 40$ & W24×62 & $\mathrm{W} 8 \times 21$ & $\mathrm{~W} 6 \times 16$ & $\mathrm{~W} 21 \times 62$ & $\mathrm{~W} 24 \times 55$ & $\mathrm{~W} 21 \times 48$ & W24×55 \\
\hline 4 & $\mathrm{~W} 8 \times 21$ & $\mathrm{~W} 12 \times 16$ & $\mathrm{~W} 12 \times 87$ & $\mathrm{~W} 33 \times 221$ & $\mathrm{~W} 27 \times 146$ & $\mathrm{~W} 14 \times 26$ & W6×8.5 & W6×8.5 & W16×26 \\
\hline 5 & $\mathrm{~W} 14 \times 145$ & $\mathrm{~W} 14 \times 176$ & W14×159 & $\mathrm{W} 14 \times 145$ & $\mathrm{~W} 14 \times 145$ & W14×109 & $\mathrm{W} 14 \times 159$ & $\mathrm{~W} 14 \times 152$ & W14 $\times 159$ \\
\hline 6 & $\mathrm{~W} 14 \times 132$ & $\mathrm{~W} 14 \times 176$ & $\mathrm{~W} 14 \times 145$ & $\mathrm{~W} 14 \times 145$ & $\mathrm{~W} 14 \times 120$ & $\mathrm{~W} 14 \times 145$ & W14×99 & $\mathrm{W} 14 \times 120$ & W14 $\times 120$ \\
\hline 7 & $\mathrm{~W} 14 \times 132$ & $\mathrm{~W} 14 \times 132$ & $\mathrm{~W} 14 \times 120$ & W14×68 & $\mathrm{W} 14 \times 26$ & W14×109 & $\mathrm{W} 14 \times 120$ & W14×109 & W14 $\times 109$ \\
\hline 8 & $\mathrm{~W} 14 \times 132$ & W14×109 & W14×99 & $\mathrm{W} 14 \times 22$ & $\mathrm{~W} 14 \times 26$ & W14×99 & $\mathrm{W} 14 \times 74$ & $\mathrm{~W} 14 \times 74$ & W14×74 \\
\hline 9 & W14×68 & $\mathrm{W} 14 \times 82$ & W14×68 & $\mathrm{W} 14 \times 48$ & $\mathrm{~W} 14 \times 53$ & $\mathrm{~W} 14 \times 53$ & $\mathrm{~W} 14 \times 74$ & $\mathrm{~W} 14 \times 82$ & W14×82 \\
\hline 10 & $\mathrm{~W} 14 \times 53$ & $\mathrm{~W} 14 \times 74$ & W14×48 & W14×68 & W14×99 & $\mathrm{W} 14 \times 43$ & $\mathrm{~W} 14 \times 43$ & $\mathrm{~W} 14 \times 43$ & W14×38 \\
\hline 11 & $\mathrm{~W} 14 \times 43$ & $\mathrm{~W} 14 \times 34$ & W14×48 & W14×132 & W14×159 & $\mathrm{W} 14 \times 34$ & $\mathrm{~W} 14 \times 30$ & $\mathrm{~W} 14 \times 34$ & $W 14 \times 53$ \\
\hline 12 & $\mathrm{~W} 14 \times 43$ & $\mathrm{~W} 14 \times 22$ & W14×34 & $\mathrm{W} 14 \times 342$ & $\mathrm{~W} 14 \times 30$ & $\mathrm{~W} 14 \times 22$ & $\mathrm{~W} 14 \times 22$ & $\mathrm{~W} 12 \times 19$ & W14×22 \\
\hline 13 & $\mathrm{~W} 14 \times 145$ & $\mathrm{~W} 14 \times 145$ & W14×109 & W14×159 & $\mathrm{W} 14 \times 145$ & $\mathrm{~W} 14 \times 120$ & $\mathrm{~W} 14 \times 90$ & W14×109 & W14×90 \\
\hline 14 & $\mathrm{~W} 14 \times 145$ & $\mathrm{~W} 14 \times 132$ & W14×82 & W14×109 & $\mathrm{W} 14 \times 26$ & W14×99 & $\mathrm{W} 14 \times 120$ & W14×109 & W14 $\times 109$ \\
\hline 15 & $\mathrm{~W} 14 \times 120$ & W14×109 & W14×99 & W14×99 & $\mathrm{W} 14 \times 74$ & $\mathrm{~W} 14 \times 109$ & $\mathrm{~W} 14 \times 90$ & W14×99 & W14×90 \\
\hline 16 & $\mathrm{~W} 14 \times 90$ & $\mathrm{~W} 14 \times 82$ & W14×109 & $\mathrm{W} 14 \times 48$ & $\mathrm{~W} 14 \times 26$ & $\mathrm{~W} 14 \times 82$ & $\mathrm{~W} 14 \times 99$ & W14×99 & W14×90 \\
\hline 17 & $\mathrm{~W} 14 \times 90$ & $\mathrm{~W} 14 \times 61$ & $\mathrm{~W} 14 \times 90$ & $\mathrm{~W} 14 \times 43$ & $\mathrm{~W} 14 \times 26$ & $\mathrm{~W} 14 \times 90$ & W14×68 & $\mathrm{W} 14 \times 68$ & W14×61 \\
\hline 18 & $\mathrm{~W} 14 \times 61$ & $\mathrm{~W} 14 \times 48$ & W14×74 & $\mathrm{W} 14 \times 53$ & $\mathrm{~W} 14 \times 26$ & $\mathrm{~W} 14 \times 61$ & $\mathrm{~W} 14 \times 61$ & $\mathrm{~W} 14 \times 61$ & W14×61 \\
\hline 19 & $\mathrm{~W} 14 \times 30$ & $\mathrm{~W} 14 \times 30$ & W14×43 & $\mathrm{W} 14 \times 176$ & $\mathrm{~W} 14 \times 370$ & $\mathrm{~W} 14 \times 38$ & $\mathrm{~W} 14 \times 43$ & $\mathrm{~W} 14 \times 34$ & W14×22 \\
\hline 20 & $\mathrm{~W} 14 \times 26$ & $\mathrm{~W} 14 \times 22$ & W14×43 & $\mathrm{W} 14 \times 211$ & $\mathrm{~W} 14 \times 109$ & $\mathrm{~W} 14 \times 22$ & $\mathrm{~W} 14 \times 22$ & $\mathrm{~W} 14 \times 22$ & W14×22 \\
\hline Best weight (lb)* & 220465 & 214860 & 194508 & 214848 & 188640 & 206520 & 203490 & 202422 & 202125 \\
\hline NSA & 15500 & 13924 & 8010 & 2074 & 1826 & 19640 & 18820 & 14572 & 18732 \\
\hline Mean weight (lb) & 229555 & 222620 & 213545 & N/A & N/A & 216475 & 208648 & 209560 & 207949.2 \\
\hline Worst weight (lb) & N/A & N/A & N/A & N/A & N/A & 243143 & 226019 & N/A & 216308.9 \\
\hline SD & 4561 & N/A & 7027 & N/A & N/A & N/A & N/A & 7052 & 4204 \\
\hline Max CV (\%) & None & None & 34 & 893 & 1766 & None & None & None & None \\
\hline
\end{tabular}

The JA has the best design weighing of $202125 \mathrm{lb}(91682$ $\mathrm{kg}$ ) in comparison to all methods reported in the table. It should be noted that the JA is overall the most efficient optimizer with the lightest feasible design and the lowest standard deviation value. The maximum interaction ratio and interstory drift of the optimum design obtained by JA are 0.95 and 0.479 in $(1.33 \mathrm{~cm})$. Although SGA [18] and EHBMO [6] found lighter designs weighing of $194508 \mathrm{lb}$ $(88227 \mathrm{~kg})$ and $188640 \mathrm{lb}(85565 \mathrm{~kg})$ respectively, these designs violate constraints at high rates as $\% 34$ and $\% 1766$.

Fig. 4 illustrates the convergence history of JA and other algorithms to the optimum design. Despite the fact that number of structural analyses required by JA is 18732 , it has the best performance in terms of convergence rate and reaching the optimum design as seen in Fig 4.

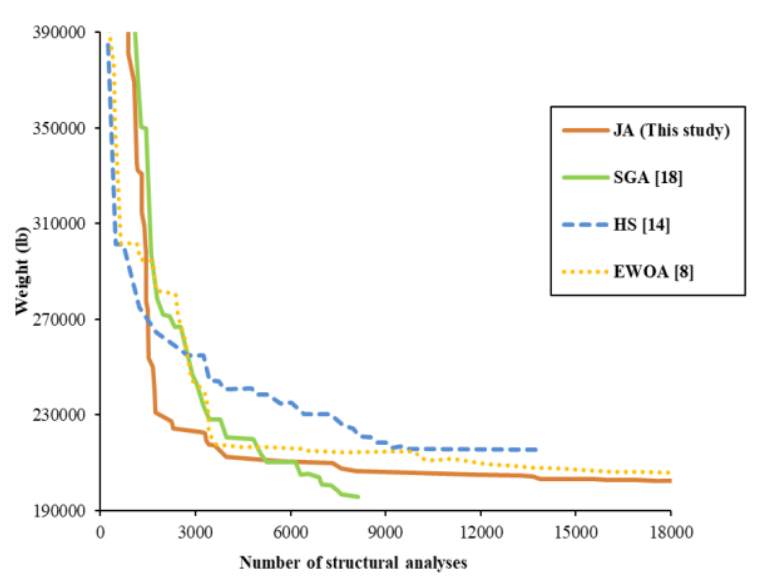

Figure 4. Comparison of convergence curves for the three-bay twenty-four story frame $(1 \mathrm{lb}=0.4536 \mathrm{~kg})$ 


\section{Conclusions}

In this study, the standard JA was modified in order to improve its performance. Two planar steel frames previously optimized by various metaheuristic optimization methods are designed to demonstrate the validity of JA. The results obtained by JA were compared with those of other state-of-art metaheuristic optimization methods. Remarkably, JA found the best design compared to all methods in both examples and strictly satisfied the design constraints. The statistical parameters obtained by different runs of JA indicate that JA has better performance than the other algorithms in terms of robustness, convergence speed and feasibility.

\section{Acknowledgement}

This research has been supported by Dicle University Scientific Research Projects Coordination Unit. Project Number: MÜHENDİSLİK. 21.004, 2021.

\section{References}

[1] D. Henderson, S.H. Jacobson, A.W. Johnson, F. Glover and G.A. Kochenberger Handbook of metaheuristics. Chapter "The Theory and Practice of Simulated Annealing," 57, 287-319. 2003.

[2] J.H. Holland. "Adaptation in natural and artificial systems,".Ann Arbor, MI: University of Michigan Press; 1975.

[3] J. Kennedy and R. Eberhart "Particle swarm optimization", In: Proceedings of IEEE international conference on neural networks. Perth, Australia, pp 19421948, 1995.

[4] M. Dorigo, V. Maniezzo and A. Colorni. "The ant system: optimization by a colony cooperating agents". IEEE Trans Syst, Man Cybern B;1(26):29-41, 1996.

[5] O. Bozorg Haddad, A. Afshar, MA Marino "Honey bees mating optimization algorithm (HBMO); a new heuristic approach for engineering optimization" In: Proc. 1 st int. conf. on modeling, simulation and applied optimization (ICMSA0/05), Sharjah, UAE; 2005 February

[6] M.R. Maheri, H. Shokrian and M.M. Narimani, "An enhanced honey bee mating optimization algorithm for design of side sway steel frames" Advances in Engineering Software, 109, 62-72, 2017.

[7] S. Mirjalili, and A. Lewis, "The whale optimization algorithm." Advances in Engineering Software, 95, 51-67, 2016.
[8] A. Kaveh and M.I. Ghazaan, "Enhanced whale optimization algorithm for sizing optimization of skeletal structures", Mechanics Based Design of Structures and Machines, 45(3), 345-362, 2017.

[9] P.J. Van Laarhoven and E.H. Aarts, "Simulated annealing. In Simulated annealing: Theory and applications" (pp. 7-15). Springer, Dordrecht, 1987.

[10] Z.W. Geem,, J.H. Kim and G.V. Loganathan, "A new heuristic optimization algorithm: harmony search", Simulation, 76(2), 60-68, 2001

[11] O.K. Erol and I. Eksin, "A new optimization method: big bang-big crunch", Advances in Engineering Software, 37(2), 106-111, 2006.

[12] A. Kaveh and V.R. Mahdavi, "Colliding bodies optimization: a novel meta-heuristic method", Computers \& Structures, 139, 18-27, 2014.

[13] C.V. Camp, B.J. Bichon and S.P. Stovall. "Design of steel frames using ant colony optimization." Journal of Structural Engineering, 131(3), 369-379, 2005.

[14] S.O. Degertekin, "Optimum design of steel frames using harmony search algorithm.", Structural and Multidisciplinary Optimization, 36(4), 393-401, 2008.

[15] M.P. Saka, M. P, “Optimum design of steel frames using stochastic search techniques based on natural phenomena: a review. Civil computations: tools and techniques", Saxe-Coburg Publications, Stirlingshire, UK, 105-147, 2007.

[16] O. Hasançebi, S. Çarbaş, E. Doğan, F. Erdal and M.P. Saka, "Comparison of non-deterministic search techniques in the optimum design of real size steel frames", Computers \& structures, 88(17-18), 1033-1048, 2010.

[17] E. Doğan and M.P. Saka, "Optimum design of unbraced steel frames to LRFD-AISC using particle swarm optimization." Advances in Engineering Software, 46(1), 27-34, 2012.

[18] F. Carraro, R.H. Lopez and L.F.F. Miguel, “Optimum design of planar steel frames using the Search Group Algorithm." Journal of the Brazilian Society of Mechanical Sciences and Engineering, 39(4), 1405-1418, 2017.

[19] M. Farshchin, M. Maniat, C.V: Camp, and S. Pezeshk, "School based optimization algorithm for design of steel frames." Engineering Structures, 171, 326-335, 2018. 
[20] R. Rao, "Jaya: A simple and new optimization algorithm for solving constrained and unconstrained optimization problems.” International Journal of Industrial Engineering Computations, 7(1), 19-34, 2016.

[21] K. Gao, Y. Zhang, A. Sadollah, and R. Su, "Jaya algorithm for solving urban traffic signal control problem" 14th International Conference on Control, Automation, Robotics and Vision (ICARCV) (pp. 1-6). IEEE, 2016

[22] L. Wang, Z. Zhang, C. Huang, and K.L. Tsui, “A GPU-accelerated parallel Jaya algorithm for efficiently estimating Li-ion battery model parameters." Applied Soft Computing, 65, 12-20, 2018.

[23] P. Ocłoń, P. Cisek, M. Rerak, D. Taler, R. Rao, A. Vallati, and M. Pilarczyk, Thermal performance optimization of the underground power cable system by using a modified Jaya algorithm. International Journal of Thermal Sciences, 123, 162-180, 2018.

[24] Z. Ding, J. Li, and H. Hao, "Structural damage identification using improved Jaya algorithm based on sparse regularization and Bayesian inference." Mechanical Systems and Signal Processing, 132, 211-231, 2019.
[25] S.O. Degertekin, L. Lamberti, and I.B. Ugur, "Sizing, layout and topology design optimization of truss structures using the Jaya algorithm." Applied Soft Computing, 70, 903-928, 2018.

[26] S.O. Degertekin, L. Lamberti, and I.B. Ugur, "Discrete sizing/layout/topology optimization of truss structures with an advanced Jaya algorithm." Applied Soft Computing, 79, 363-390, 2019.

[27] AISC-LRFD, "Manual of steel construction. Load and resistance factor design". Metric conversion of the second edition, vol. I \& II. AISC; 1999.

[28] The MathWorks, MATLAB ${ }^{\circ}$ Version R2017a, Austin (TX) USA.

[29] S. Mazzoni, F. McKenna, M.H. Scott, and G. Fenves, OpenSees command language manual. Pacific Earthquake Engineering Research (PEER) Center, 264, 2006

[30] P. Dumonteil, W. Moore, "Simple Equations for Effective Length Factors-Discussion.” Eng J-Am Inst Steel Constr INC; 30:37-37, 1993.

[31] J.H. Davison and P.F. Adams, "Stability of braced and unbraced frames", Journal of the Structural Division, 100(2), 319-334, 1974. 